\title{
Research on Control Algorithm of Water-tank Water Level Control System
}

\author{
Mianmian Dong and Baoyi Guo \\ School of Electronic Information Engineering, Xi'an Technological University, \\ $X i^{\prime} a n$ \\ 710021, PR China \\ 30853429@qq.com
}

\begin{abstract}
To eliminate control error of water level, this paper researches the control algorithm of water-tank in water level control system, and uses the fuzzy controller to improve the control performance, two-dimensional fuzzy controller is designed taking advantaging of Fuzzy Logic Controller, set up the structure mode of the water-tank water level control system according to the characteristics of the water-tank water level control system, give the simulation result of the performance of the fuzzy controller, acquiring waveform graphs of real water level and fixed level, and compared with PID controller. The simulation results show that the fuzzy controller has better control performance than the PID controller.
\end{abstract}

Keywords: water level control, fuzzy controller, simulation

\section{Introduction}

The traditional water level monitoring in water-tank is realized by a float or simpler manual monitoring, but it is imprecise and difficult to control for traditional monitoring methods. To the tank-water device of providing water for the users and fire, the traditional control methods make water overflow or shortage, in some emergency cases, which will cause great distress for human life[1-2]. In order to solve these questions, it is necessary to design a controller which can automatically control water level and keep the position of the water level unchanged.

Methods of controlling water-tank water level have traditional control method and intelligent control method [3]. The traditional control methods are established on the basis of the accurate mathematical model of the controlled objects, then building the control structure model through the mathematical formula of system influence factors. However, in practice and mixed use, there are many interference factors in the water-tank control system, such as: the fluctuation of water level, leaking, unstable water flow speed and so on [4-5]. These interference factors can't be described by the mathematical formula; the traditional control methods have many flaws to some extent, so it is necessary to introduce intelligent control to improve the control performance of the system [6]. The fuzzy Control is an intelligent control, and also a closed-loop feedback control, which don't need to build model of the controlled objects. The fuzzy controller is easy to come true and build, with good stability and strong adaptability. The PID control and the fuzzy control are applied to the water level control system, in addition, simulating and verifying the performance of the fuzzy controller and the conventional PID controller. 


\section{The Principle of the Water Level}

The purpose of the tank water level control system is to overcome all the interference factors to keep the water level unchanged. The structure of the water level control system includes pipeline linking liquid line, valve, water-tank, Liquid Level Sensor, water pump and electric regulating valves. The control process of system: Firstly, the water level signal which is detected by liquid level sensor is amplified, and then the amplified signal is converted into digital signal by the $\mathrm{AD}$ converter, the error is that the digital signal is subtracted from the given value[7]. Finally, the error E and the error rate of change EC are regarded as input data of MCU, designed fuzzy control algorithm program have been stored in the MCU, the output can control the size of electric control valve to control the speed of the water in order to make sure that the water-tank water level is a fixed position. Tank level fuzzy inference system as shown in Figure 1.

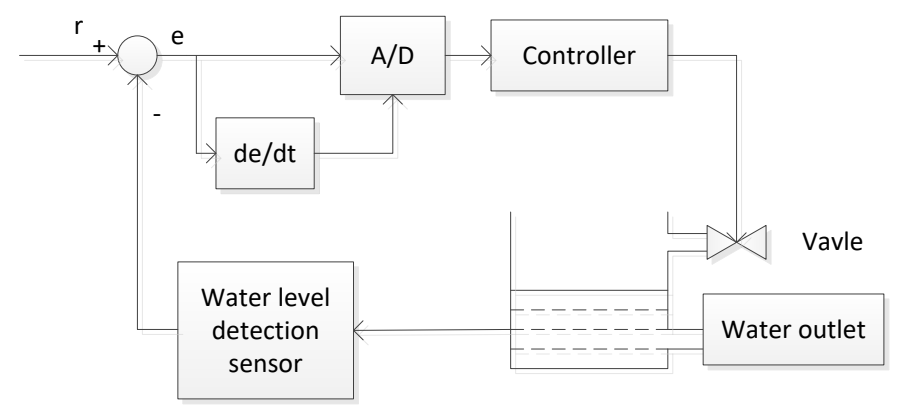

Figure 1. Tank Level Fuzzy Control System

\section{The Design of Fuzzy Control System}

The structure of fuzzy control system is composed of the traditional feedback control system on the basis of the fuzzy inference system; the main component of the fuzzy inference system is fuzzy controller, which includes the fuzzy processing of the input and output variables, the design of fuzzy rule, fuzzy inference, fuzzy solution, etc[8]. This paper selects the two-dimensional fuzzy controller, the input variables of the fuzzy control system are error and rate of error, and the output variable is valve control signal. The fuzzy control rules are generated according to the fuzzy relationship between the input variables and human experience, eventually the fuzzy control rule table of realizing the automatic control of water level is established. The function of the output variable is controlling the opening of the valve in order to keep the water level unchanged. The fuzzy control system block diagram is shown in Figure 2.

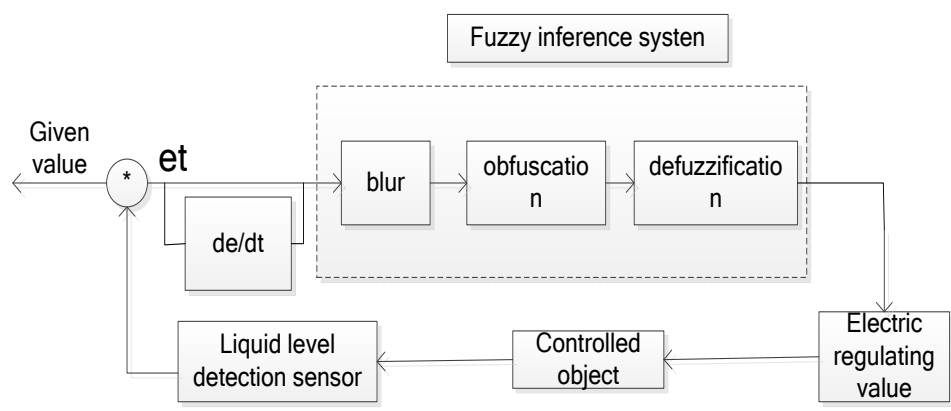

Figure 2. The Fuzzy Control System Block Diagram 


\subsection{Determining the Fuzzy Subset and Fuzzing the Input and Output}

The output of the liquid level sensor is a continuous variable, however, the input of the fuzzy controller is a discrete variable based on the fuzzy logic, so it is necessary to fuzzy the input data, the basic range of error and output variables of water-tank water level system are set up to be -1 to 1 , the quantity fields are -3 to 3 and quantitative factor is 3 ; The basic range of the error rate of change are -0.1 to 0.1 , the quantity are -3 to 3 and quantitative factor is 0.03 .

When the system error is smaller, it is better to choose the narrower and thinner membership function, which has a higher resolution and can improve the sensitivity of the system. When the system error is larger, it is better to choose the wider and fatter membership function, which has a lower resolution and can improve the stability of the system[9]. This paper chooses membership function of Triangle and Gauss function through the analysis of control system, in order to improve the sensitivity of the system under the conditions of stably working. The fuzzy language of the system is set up to be seven levels: "NB" , "NM" , "NS" , "ZE", "PS" , "PM","PB". Among them the NB and PB are Gauss function curve. The membership functions of error $\mathrm{E}$, error rate of change and the output variables $U$ are shown in Figure 3.

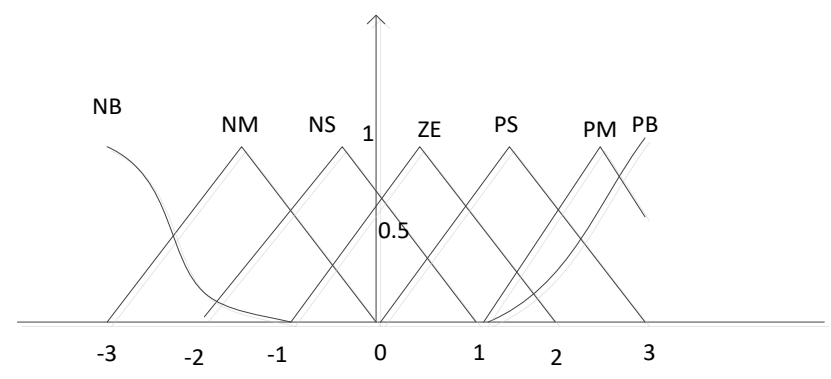

Figure 3. Membership Functions of Input and Output Variables

The ranges of input and output variables are discrete, and the numbers of discrete variables are limited, the membership function of the fuzzy set can be described by the numerical method. Assignment table of the membership function of the variables are shown in Table 1.

Table 1. Assignment Table of the Membership Function of the Variables

\begin{tabular}{|c|c|c|c|c|c|c|c|}
\hline Value Element & -3 & -2 & -1 & 0 & 1 & 2 & 3 \\
\hline NB & 1 & 0.2 & 0 & 0 & 0 & 0 & 0 \\
\hline NM & 0 & 0.65 & 0.65 & 0 & 0 & 0 & 0 \\
\hline NS & 0 & 0 & 0.65 & 0.65 & 0 & 0 & 0 \\
\hline ZE & 0 & 0 & 0 & 0.65 & 0.65 & 0 & 0 \\
\hline PS & 0 & 0 & 0 & 0 & 0.65 & 0.65 & 0 \\
\hline PM & 0 & 0 & 0 & 0 & 0 & 0.65 & 0.65 \\
\hline PB & 0 & 0 & 0 & 0 & 0 & 0.2 & 1 \\
\hline
\end{tabular}

\subsection{The Fuzzy Rule Base of Fuzzy Controller}

The fuzzy control rules can ensure that the output of the controller makes dynamic characteristic of the system output response in the best state, it can acquire fuzzy rules through continuous practice and human experiences. The fuzzy rule is described by the statement of "if E and EC then U" .If the error is negative and small, it need determine that the error is how to change according to the error rate of change in order to avoid the 
overshoot of the system. When the error rate of change is positive, which shows that the error has a tendency of decreasing, so the control variable is smaller; when the error rate of change is negative, which shows that the error has a tendency of increasing, at this time the control variable is larger [10]. So the following table is summarized according to the control rules, as shown in Table 2 .

Table 2. The Fuzzy Rule Base of the Water Level System

\begin{tabular}{|c|c|c|c|c|c|c|c|}
\hline $\mathrm{U}$ & & & & & & & \\
\hline & NB & $\mathrm{NM}$ & NS & $\mathrm{ZE}$ & PS & $\mathrm{PM}$ & PB \\
\hline NB & PS & PS & PS & PS & $\mathrm{PM}$ & PB & PB \\
\hline NM & NS & PS & PS & PS & $\mathrm{PM}$ & $\mathrm{PM}$ & PB \\
\hline NS & NM & NS & ZE & $\mathrm{ZE}$ & PS & $\mathrm{PM}$ & PM \\
\hline $\mathrm{ZE}$ & NB & $\mathrm{NM}$ & NS & $\mathrm{ZE}$ & PS & $\mathrm{PM}$ & $\mathrm{PM}$ \\
\hline PS & NB & $\mathrm{NM}$ & NS & $\mathrm{ZE}$ & $\mathrm{ZE}$ & PS & PM \\
\hline $\mathrm{PM}$ & NB & NB & NM & NS & NS & PS & PS \\
\hline PB & NB & NB & NM & NS & NS & NS & NS \\
\hline
\end{tabular}

\subsection{The Fuzzy Inferential Method of Fuzzy Controller}

In order to achieve the real time and fast control of the system ,the fuzzy output variable can be acquired by the fuzzy control rule table, which is calculated through that the fuzzy rule base taking advantage of Mamdani fuzzy inferential method[11] .

The process of the Mamdani fuzzy inference: First, the fuzzy relations $R$ described by all the fuzzy rule are calculated, as shown in formula (1) to (3); Then, all the fuzzy control relations $\mathrm{R}$ are calculated which can describe the water level control system, namely, $R=R_{1} \cup R_{2} \cup \cdots \cup R_{\mathrm{N}} \cdot \cup$ show the intersection of each element of all matrices; Finally, the fuzzy query table are built[12].

$$
\begin{aligned}
& R_{1}=N L(E) \times N L(E C)=N L^{T} \cdot N L \\
& {\left[\begin{array}{c}
1 \\
0.2 \\
0 \\
0 \\
0 \\
0 \\
0 \\
0 \\
0
\end{array}\right] .\left[\begin{array}{lllllllll}
0 & 0 & 0 & 0 & 0 & 0 & 0 & 0.2 & 1
\end{array}\right]=\left[\begin{array}{ccccccccc}
0 & 0 & 0 & 0 & 0 & 0 & 0 & 0.2 & 1 \\
0 & 0 & 0 & 0 & 0 & 0 & 0 & 0.2 & 0.2 \\
0 & 0 & 0 & 0 & 0 & 0 & 0 & 0 & 0 \\
0 & 0 & 0 & 0 & 0 & 0 & 0 & 0 & 0 \\
0 & 0 & 0 & 0 & 0 & 0 & 0 & 0 & 0 \\
0 & 0 & 0 & 0 & 0 & 0 & 0 & 0 & 0 \\
0 & 0 & 0 & 0 & 0 & 0 & 0 & 0 & 0 \\
0 & 0 & 0 & 0 & 0 & 0 & 0 & 0 & 0 \\
0 & 0 & 0 & 0 & 0 & 0 & 0 & 0 & 0
\end{array}\right]}
\end{aligned}
$$

The column vector $R_{1}$ is straight for the row vector $R_{1}^{T}$ :

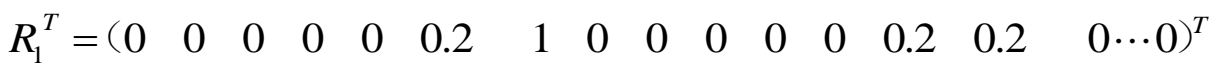

The fuzzy relationship matrix: 


$$
\begin{aligned}
& R_{1}=R_{1}^{T} \cdot U 1 \\
& =\left(\begin{array}{cccccccccccccccc}
0 & 0 & 0 & 0 & 0 & 0.2 & 1 & 0 & 0 & 0 & 0 & 0 & 0.2 & 0.2 & 0 \cdots 0
\end{array}\right)^{T} \circ\left(\begin{array}{lllllll}
0 & 0 & 0 & 0 & 0.65 & 0.65 \\
0 & \cdots & 0 & 0 \\
\cdots & \cdots & \cdots & \cdots \\
0 & \cdots & 0.2 & 0 \\
\cdots & \cdots & \cdots & \cdots \\
0 & \cdots & 0.2 & 0 \\
\cdots & \cdots & \cdots & \cdots \\
0 & \cdots & 0 & 0 \\
0 & 0 & 0 & 0
\end{array}\right\}_{49 \times 7}
\end{aligned}
$$

In the same way, all the fuzzy relations are deduced from the corresponding rules by deducing the 49 fuzzy rules; the fuzzy matrix of the whole rules is calculated by taking the union of the fuzzy relations, as shown in formula (4).

$$
R=R_{1} \cup R_{2} \cup \cdots \cup R_{49}
$$

When the input variables are determined, the fuzzy relations of the fuzzy rules can calculated, and then the fuzzy set of seven output variables are obtained by taking the intersection of each element of the fuzzy relations and the general fuzzy matrix ,as shown in formula (5).

$$
U=\frac{v_{1}}{-3}+\frac{v_{2}}{-2}+\frac{v_{3}}{-1}+\frac{v_{4}}{0}+\frac{v_{5}}{1}+\frac{v_{6}}{2}+\frac{v_{7}}{3}
$$

\subsection{Defuzzification}

The output variable gained by querying the fuzzy control rule table is fuzzy-valued, so it is necessary to convert the fuzzy value into the exact value in order to control the valve by the fuzzy solution method. The method of the fuzzy solution chooses the gravity method of the area, which can make the output signal smooth when the input signal has small changes. The calculation formula is shown in (6).

$$
U=\frac{\sum_{i=1}^{n} v\left(U_{i}\right) \cdot U_{i}}{\sum_{i=1}^{n} v\left(U_{i}\right)},
$$

In (6), $i=1,2, \ldots 7 . U_{\mathrm{i}}$ is the first $i$ language variable of the output variables, $U=v\left(U_{i}\right)$ is membership function value of the output $U_{\mathrm{i}}$ from the first $i$ fuzzy rule.

\section{The Simulation of the Water-Tank Water Level Control System}

The fuzzy controller has been designed according to the working principle of the water-tank, the performance of the fuzzy controller is simulating in which input variables are error and error rate of change and the output variable is the valve control signal in MATLAB/SIMULINK.

Firstly, the fuzzy inference relationship of the two-dimensional fuzzy controller in the fuzzy toolbox of MATLAB is established, the schematic diagram of the inference system include two input variables and an output variable as shown in Figure 4, the membership function of input and output variables as shown in Figure 5, the designed fuzzy control rule base as shown in Figure 6,the observer of the control rules as shown in Figure 7, The three-dimensional curved surface between the input and output variables as shown in Figure 8 . 


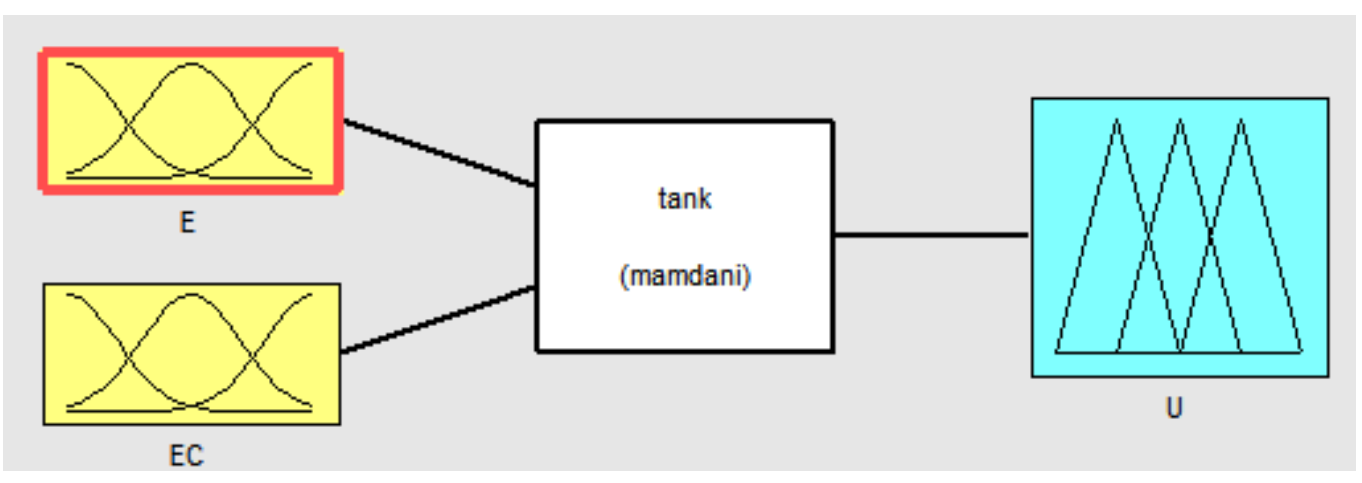

Figure 4. Fuzzy Inference Relations

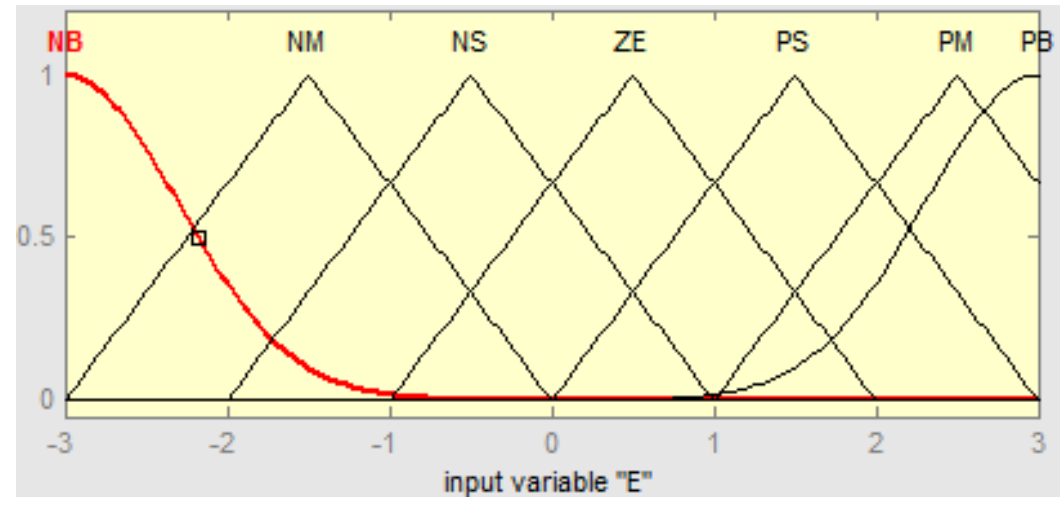

Figure 5. Membership Function of Input Variable

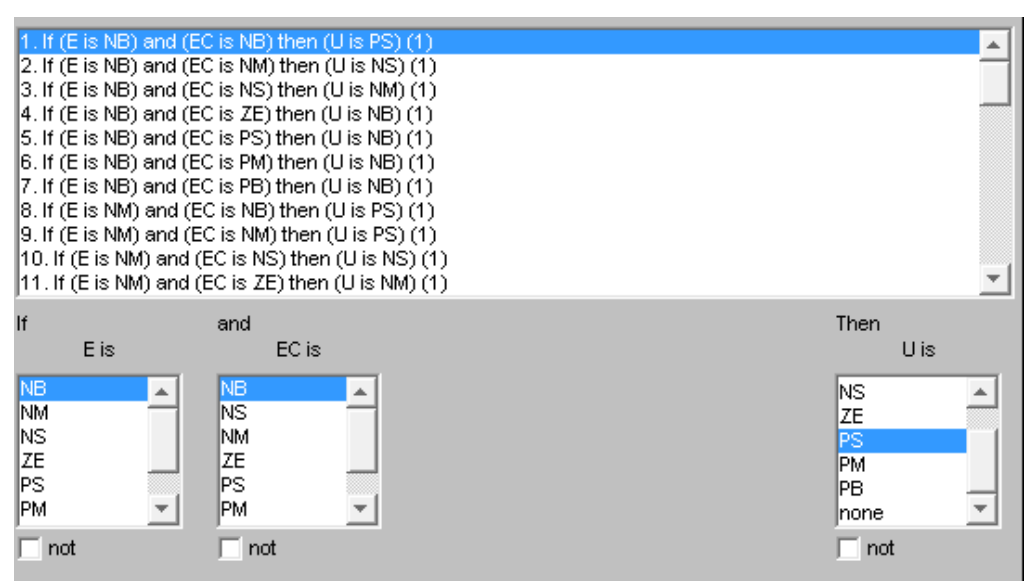

Figure 6. The Fuzzy Rule Base 


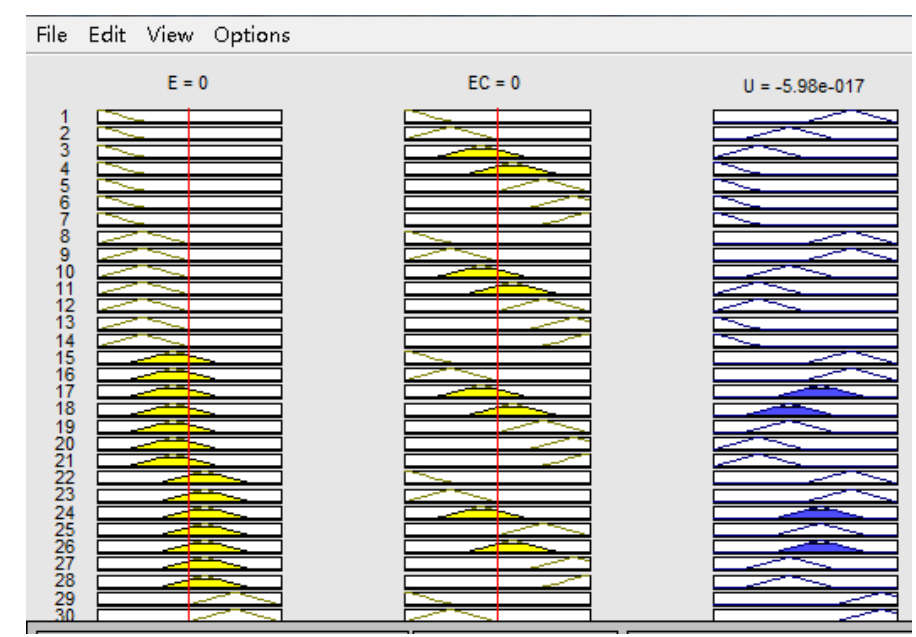

Figure 7. The Fuzzy Control Rule

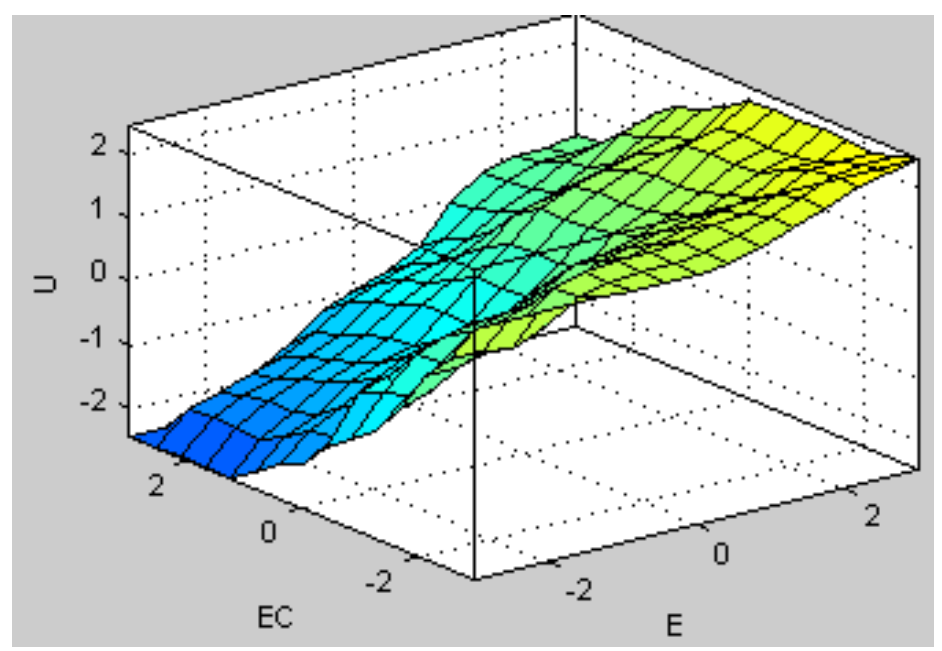

Figure 8. The Three-Dimensional Curved Surface of Input and Output Variables

Because the system has the error, when error is -2 ,error rate of change is -0.725 , the output is 0 ; when the error is -2 , the error rate of change is 1.23 , then the output is-1.6, when the error is -2 , the error rate of change is -1.5 , then the output is 0.303

\section{The Performance Simulation of the Water-Tank Water Level Fuzzy Control System}

The structural model of fuzzy control system of the water-tank water level in the SIMULINK toolbox of MATLAB is shown in Figure 9, the control system is mainly composed of five parts, including signal generator, water-tank system module, fuzzy control module, the oscilloscope, the PID controller. The switch connects PID controller when the property constant 1 of the switch is more than 0 , the system simulates PID controller, the structure of the PID controller is shown in Figure 10.The output waveform of the real water level and the given water level are shown in Figure 11.

When the property constant 1 of the switch is less than 0 , the switch connects fuzzy controller, at this time the icon of fuzzy controller is clicking in order to fuzzy controller, the system simulates fuzzy controller, the simulation waveform of the water level is shown in Figure 12. 


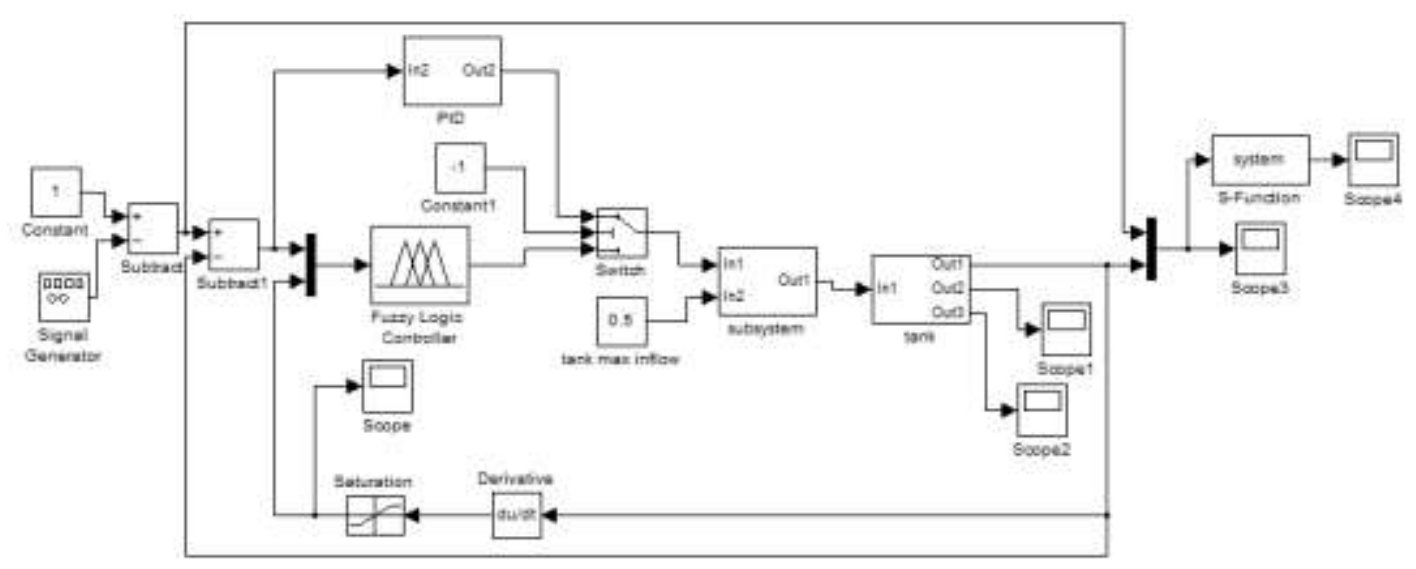

Figure 9. The Structural Model of Fuzzy Control System of the Water-Tank Water Level

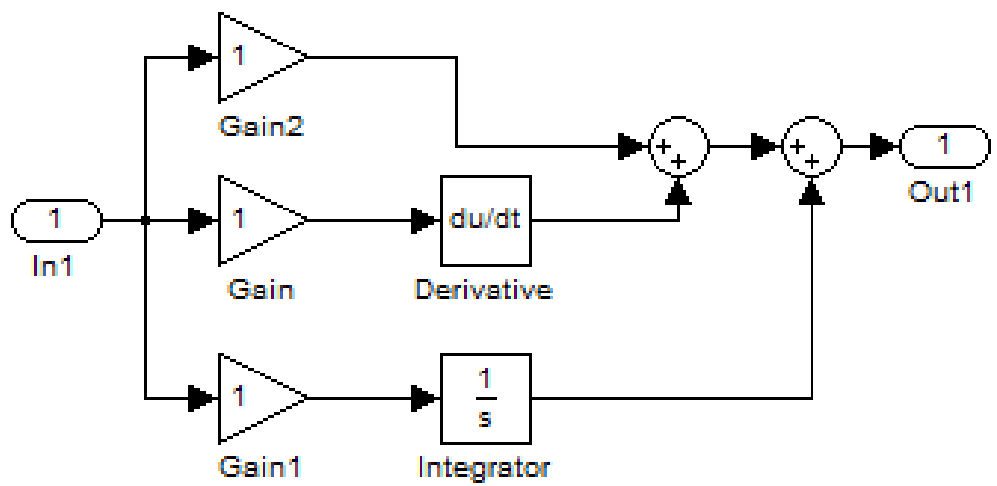

Figure 10. The Traditional PID Controller

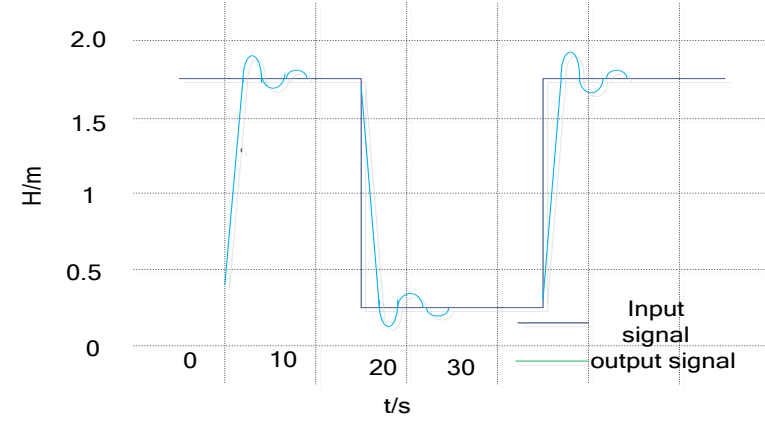

Figure 11. The Simulation Waveform of PID Control System of Water-Tank Water Level 


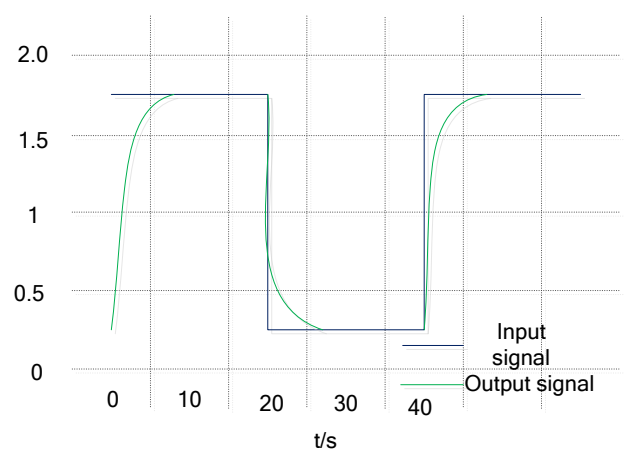

Figure 12. The Simulation Waveform of Water-Tank Water Level Fuzzy Control System

Table 3 is the results by comparing Figure 11 with Figure 12.

\section{Table 3. The Performance of the Simulation Result}

\begin{tabular}{|l|l|l|}
\hline Controller & PID & Fuzzy \\
\hline Overshoot & $8.9 \%$ & $3.7 \%$ \\
\hline Response time & $9 \mathrm{~s}$ & $7 \mathrm{~s}$ \\
\hline
\end{tabular}

From the Table 3, it can be seen that the overshoot of the fuzzy controller is better than the conventional PID controller; the response time of the fuzzy controller has 2 s faster than PID controller.

\section{Conclusions}

The paper research the performance of water-tank liquid level control system on the basis of methods of the fuzzy control and the traditional PID control, the fuzzy controller is designed, the input of which are the error and error rate of change of the water-tank water level system, and the fuzzy rules are built according to human experience, then fuzzy solution take advantage of the center of gravity method, finally, it can achieve the adaptive control of water level in order to keep the water level unchanged. The structural model of fuzzy control system of the water-tank water level is built and simulated under the condition of the two controllers. The simulation results show that the performance of the fuzzy control has better control than the conventional PID controller in the water tank level control system.

\section{References}

[1] J.-L. Song, Y. Yang and K.-K. Xu, "Active Disturbance Rejection Control of the Stabilizing Circuits for Inertial Platform", Journal of System Simulation, vol. 14, no. 391, (2002).

[2] X.R. Song and H. Chen, "Research on Adaptive AUV Tracking Control System Based on Least Squares Support Vector Machine", Computer Modeling and New Technologies, vol. 18, no. 33, (2014).

[3] H. S. Yan and D. Xu, "An approach to estimating product design time based on fuzzy v-support vector machine", IEEE Transactions on Neural Networks, vol. 18, no. 72, (2009).

[4] C. Sung Moon, H. O. Sang and L. Soo-Young, "Support Vector Machines with Binary Tree Architecture for Multi-Class Classification", Neural Information Processing Letters and Reviews, vol. 2, no. 47, (2004).

[5] H. Li, J. Gao and Z. Wang, "Target location fire precision test technology by using intersectingphotoelectric detection target", Optik, vol. 125, no. 1325, (2014).

[6] G. Chen, X. Wang, S. Fan, H. Tang, L. Lin and A. Wang, "ESD-Induced Noise to Low Noise Amplifier Circuits in BiCMOS Original Research Article", Tsinghua Science \& Technology, vol. 15, no. 259, (2010). 
[7] S.K. Nayar, K. Ikeuchi and T. Kanade, "Surface reflection:Physical and Geometrical Perspectives", IEEE Transactions on Pattern. Analysis and Machine Intelligence, vol. 13, no. 611, (1991).

[8] F. Pastor and E. Loute, "Limit analysis decomposition and finite element mixed method Original Research Article", Journal of Computational and Applied Mathematics, vol. 234, no. 2213, (2010).

[9] H. Li and Z. Lei, "Study and analysis on a new optical detection design method for photoelectric detection target", Sensor review, vol. 33, no. 315, (2013).

[10] C. Wang and J. Wei, "Photoelectric imaging system in the analysis of atmospheric transmission characteristics calculation problems", Journal of Beijing institute of technology, vol. 23, no. 617, (2003).

[11] C. Lei, S. Zhang and X. Guan, "Extended target optical properties of the theoretical analysis and the research", Laser and particle beam, vol. 25, no. 1671, (2013).

[12] J.-Y.Zhang, M. Ji and H.-L. Wang, "Modeling and simulation of airborne stabilized sighting system", Journal of Applied Optics, vol. 27, no. 491, (2006).

\section{Authors}

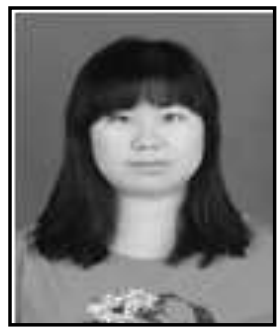

Mianmian Dong (1981- ), she is a Lecturer, Master of Engineering, graduated from Xidian University, Shaanxi Xi'an, China. The main research direction is communication and information processing.

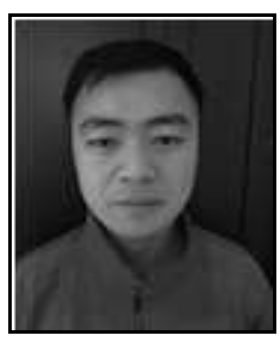

Baoyi Guo(1979-), he is a Lecturer. Master of Engineering, graduated from Xi'an Technological University, Shaanxi Xi'an, China.. The main research direction is control theory and control engineering. 